\title{
Primary amyloidosis and severe intrahepatic cholestatic jaundice
}

\author{
R A Peters, G Koukoulis, A Gimson, B Portmann, D Westaby, R Williams
}

\begin{abstract}
Liver involvement in systemic amyloidosis is frequent but is rarely of clinical importance. Five patients with severe cholestatic jaundice are described and an additional 20 from published reports are reviewed. The most frequent presenting symptoms were lethargy and abdominal pain, which were present for a median of 11 months before the onset of jaundice. Hepatomegaly, usually marked, was present in $92 \%$, with ascites in $56 \%$ of the cases. The serum bilirubin concentration was noticeably high and the serum globulin low. Histology of the liver showed considerable perisinusoidal deposition with a slight predilection for the periportal area. Two patients presented with predominant centrilobular deposition. Congo red staining was not uniformly positive. A variety of treatment regimens was tried but median survival was only three months from the onset of jaundice. (Gut 1994; 35: 1322-1325)
\end{abstract}

In 1971, when Levy et al ${ }^{1}$ described a patient with severe cholestatic jaundice and primary amyloidosis, a review of the published reports revealed another four patients with a similar syndrome. Rubinow et $a l^{2}$ in 1978 reported a further four patients, and with their review of the published studies brought the total to 12 cases. Since then another eight cases have been described in studies published in English, and if the present series is included the total is $25 .^{3-9}$ Primary (AL) amyloidosis is characterised by the deposition of an abnormal extracellular protein in the form of fibrils which are derived from monoclonal immunoglobulin light chains. One of the most important properties of these fibrils is their continuous accumulation, which is responsible for the functional damage to organs and tissues. ${ }^{10}$ Although hepatic involvement in AL amyloidosis is frequent, this is seldom of clinical importance with hepatomegaly in one third of the patients or only a mildly raised alkaline phosphatase activity. ${ }^{11}$

In this report, we describe five patients with severe cholestatic jaundice associated with $\mathrm{AL}$ amyloidosis and review the published reports in an attempt to identify the important clinical, biochemical, and histopathological features of the syndrome and the prognosis.

Case histories

The five patients were referred to the Institute of Liver Studies between 1984 and 1990.
CASE 1

A 59 year old Irish man presented with a one year history of lethargy and two months of painless cholestatic jaundice. On examination he was found to be deeply jaundiced, confused, with slurred speech and asterixis (grade 1 encephalopathy). The liver was considerably enlarged and there was minimal ascites. Abnormal laboratory findings included, thrombocytosis $(602000 / \mathrm{ml})$, total protein $62 \mathrm{~g} / 1$, albumin $28 \mathrm{~g} / 1$, bilirubin 548 $\mu \mathrm{mol} / \mathrm{l}$, alkaline phosphatase (ALP) $1113 \mathrm{U} / \mathrm{l}$, aspartate aminotransferase (AST) $117 \mathrm{U} / 1$, gamma glutamyl transpeptidase (GGT) 58 $\mathrm{U} / 1$, and prothrombin time $17 / 12$ seconds. Protein electrophoresis showed a monoclonal band in the beta 2 position, with free kappa light chains in the urine on immunofixation. Ultrasound scanning showed hepatomegaly with a homogeneous echo pattern. A liver biopsy showed considerable amyloid infiltration and a bone marrow biopsy normal cellular components with patchy amyloid deposits. The patient was treated with prednisolone and melphalan, as well as with spironolactone for control of his ascites. His encephalopathy improved but not the jaundice. The patient was discharged to complete another course of chemotherapy but he developed rapidly increasing jaundice and renal failure and died two weeks after discharge.

\section{CASE 2}

A 55 year old Cypriot presented initially with increasing lethargy and weakness. Six months later he was noticed to be jaundiced. A laparotomy was performed but no biliary obstruction was found, and a liver biopsy was interpreted as unspecific. After this he remained lethargic and had increasing weight loss. He was referred to the Institute of Liver Studies three months later. On examination he was found to be deeply jaundiced with a $5 \mathrm{~cm}$ smooth non-tender hepatomegaly but no stigmata of chronic liver disease. Laboratory findings included, urea $9.9 \mathrm{mmol} / \mathrm{l}$, creatinine $136 \mathrm{mmol} / \mathrm{l}$, total protein $63 \mathrm{~g} / \mathrm{l}$, albumin 35 $\mathrm{g} / 1$, bilirubin $567 \mu \mathrm{mol} / 1$, ALP $1135 \mathrm{U} / \mathrm{l}$, GGT $80 \mathrm{U} / 1$. IgG $8.8 \mathrm{~g} / 1$, IgA $0.25 \mathrm{~g} / 1$, IgM $1.1 \mathrm{~g} / \mathrm{l}$. Protein electrophoresis was normal but urine Bence-Jones proteins were detected, with kappa light chains on immunoelectrophoresis. Ultrasound scan of the abdomen showed a moderately enlarged liver with increased reflectivity and a spleen enlarged to $14.3 \mathrm{~cm}$. Liver biopsy showed intense amyloid infiltration and a bone marrow biopsy diffuse background staining of amyloid. For symptomatic relief he was started on $20 \mathrm{mg}$ 
of prednisolone. He returned to Cyprus were he died two weeks later of progressive liver and renal failure.

CASE 3

A 61 year old man presented initially with epigastric pain and an endoscopy showed a peptic ulcer which was treated with an $\mathrm{H}_{2}$ antagonist. Five months later he began to feel lethargic and subsequently developed pale stools, dark urine, and pruritus. When admitted to the Institute of Liver Studies he was deeply jaundiced with spider naevi, palmar erythema, and leuchonychia. There was moderate ascites but no hepatosplenomegaly. Laboratory findings included a prothrombin time of 19 seconds with a control of 15 , urea $25.7 \mathrm{mmol} / \mathrm{l}$, creatinine $172 \mathrm{mmol} / \mathrm{l}$, total protein $43 \mathrm{~g} / \mathrm{l}$, albumin $27 \mathrm{~g} / \mathrm{l}$, bilirubin 452 $\mathrm{mmol} / \mathrm{l}$, AST $63 \mathrm{U} / \mathrm{l}$, ALP $793 \mathrm{U} / \mathrm{l}, \mathrm{GGT} 228$ $\mathrm{U} / \mathrm{l}, \mathrm{IgG} 6.3 \mathrm{~g} / \mathrm{l}$, IgA $2.6 \mathrm{~g} / \mathrm{l} \operatorname{IgM} 1.2 \mathrm{~g} / 1$. The 24 hour urinary protein value was $2 \cdot 67 \mathrm{~g}$. Ultrasound scan of the abdomen showed moderate ascites and a normal sized liver with noticeably reduced parenchymal reflectivity. The patient continued to deteriorate rapidly with the development of inotrope resistant hypotension and he died of heart failure one week after his admission to hospital. Request for autopsy was refused but a post mortem liver biopsy showed severe cholestasis with dense intrahepatic deposits of amyloid protein.

\section{CASE 4}

A 75 year old woman developed abdominal discomfort, followed by anorexia and weight loss of approximately $7 \mathrm{~kg}$. Two months later she noticed pale stools and dark urine. When referred to the Institute of Liver Studies she was jaundiced with a smooth, non-tender, $2 \mathrm{~cm}$ hepatomegaly but no ascites or splenomegaly. Laboratory findings included, prothrombin ratio 1.6 , total protein $63 \mathrm{~g} / \mathrm{l}$, albumin $33 \mathrm{~g} / \mathrm{l}$, bilirubin $189 \mathrm{mmol} / \mathrm{l}$, AST $115 \mathrm{U} / \mathrm{h}, \mathrm{ALP} 1036 \mathrm{U} / \mathrm{l}, \mathrm{GGT} 534 \mathrm{U} / \mathrm{l}$. IgG $14.8 \mathrm{~g} / \mathrm{l}$, IgA $3.94 \mathrm{~g} / \mathrm{l}$, IgM 0.89 g/l. Protein electrophoresis was normal. Ultrasound scan of the abdomen showed hepatomegaly with normal reflectivity and normal spleen. Liver biopsy (performed under fresh frozen plasma cover) showed massive parenchymal deposition of amyloid. The patient continued to deteriorate and died two months later of liver failure.

\section{CASE 5}

A 51 year old man developed painless abdominal distension followed by pruritus and an increasing number of spider naevi on his face. Three months before admission he noticed black stools and was admitted to his local hospital with a frank haematemesis that required blood transfusions. An endoscopy showed oesophageal varices with evidence of recent bleeding and the patient was referred to the Institute of Liver Studies. On admission he was noticeably jaundiced with excoriated skin.
TABLE I Analysis of clinical symptoms in the 25 cases of primary amyloidosis with cholestatic jaundice

\begin{tabular}{|c|c|c|c|}
\hline & $\begin{array}{l}\text { This } \\
\text { series }\end{array}$ & $\begin{array}{l}\text { Published } \\
\text { reports }\end{array}$ & (\%) \\
\hline \multicolumn{4}{|l|}{ Symptoms $(n=17)$ : } \\
\hline Lethargy & 4 & 6 & (58) \\
\hline Abdominal pain & 2 & 6 & (47) \\
\hline Weight loss & 1 & 4 & (29) \\
\hline \multicolumn{4}{|l|}{ Signs $(n=25)$ : } \\
\hline Hepatomegaly & 3 & 20 & (92) \\
\hline Ascites & 4 & 10 & (56) \\
\hline Splenomegaly & 2 & 5 & (28) \\
\hline Oedema & 1 & 4 & (20) \\
\hline Gastrointestinal bleeding & 1 & 4 & (20) \\
\hline Spider naevi & 2 & 1 & (12) \\
\hline
\end{tabular}

$\mathrm{n}=$ Denotes number of cases in which sufficient information was given.

Tense ascites was present, and the liver and spleen were not palpable. Laboratory findings included haemoglobin $12 \cdot 1 \mathrm{~g} / \mathrm{dl}$, white cell count $16.710 \times 9 / \mathrm{ml}$, platelets $558000 / \mathrm{ml}$, and prothrombin ratio 1.24 ; urea $8.6 \mathrm{mmol} / \mathrm{l}$, creatinine $153 \mathrm{mmol} / \mathrm{l}$, total protein $52 \mathrm{~g} / \mathrm{l}$, albumin $33 \mathrm{~g} / \mathrm{l}$, bilirubin $440 \mu \mathrm{mol} / 1$, AST 139 $\mathrm{U} / \mathrm{l}, \mathrm{ALP} 1625 \mathrm{U} / \mathrm{l}$, and GGT $277 \mathrm{U} / \mathrm{l}$. The IgG was $5.46 \mathrm{~g} / \mathrm{l}$, IgA $1.83 \mathrm{~g} / \mathrm{l}$, and IgM $0.5 \mathrm{~g} / \mathrm{l}$. Protein electrophoresis did not show a monoclonal band. Ultrasound scan of the abdomen showed a liver of mildly increased size with normal reflectivity and no splenomegaly.

The patient experienced further variceal bleeding that required endoscopic sclerotherapy. He became progressively oliguric, hypotensive, and died from hepatorenal failure one week later. Necropsy examination showed amyloid deposition in liver, kidneys, pancreas, heart, and the adrenal glands.

\section{Analysis of previously reported and present cases}

The presenting features, physical findings, biochemical data, and histopathological results are summarised and compared with those previously reported in Tables I-IV. The total series comprised 16 men and nine women with a median age at the time of diagnosis of 60 years (range $29-80$ ).

The duration of the symptoms before the onset of jaundice ranged from 2 to 36 months (median 7.5 months). The most frequent of the extrahepatic amyloid syndromes were proteinuria (present in $14(56 \%)$ of the patients at the time of presentation) congestive cardiac failure (in four $(16 \%)$ ), and orthostatic hypotension (in only two cases).

TABLE II Analysis of liver function tests in the 25 cases of primary amyloidosis and cholestatic jaundice

\begin{tabular}{|c|c|c|c|}
\hline & $\begin{array}{l}\text { This } \\
\text { series }^{\star}\end{array}$ & $\begin{array}{l}\text { Published } \\
\text { reportst }\end{array}$ & Median \\
\hline $\begin{array}{l}\text { Bilirubin }(\mu \mathrm{mol} / 1) \\
\quad(5-17 \mu \mathrm{mol} / 1) \\
\text { ALP (U/1) }(<120 \mathrm{U} / \mathrm{l}) \\
\text { AST (U/1) }(<50 \mathrm{U} / 1) \\
\text { Albumin }(\mathrm{g} / \mathrm{l})(35-55 \mathrm{~g} / \mathrm{l}) \\
\text { Globulin }(\mathrm{g} / \mathrm{l})(27-33 \mathrm{~g} / \mathrm{l})\end{array}$ & $\begin{array}{r}452 \\
1113 \\
115 \\
33 \\
28\end{array}$ & $\begin{array}{c}340(n=18) \\
950(n=16) \\
71(n=16) \\
26(n=15) \\
34(n=8)\end{array}$ & $\begin{array}{r}332 \\
1000 \\
67 \\
27 \\
30\end{array}$ \\
\hline
\end{tabular}

$\mathrm{n}=$ Number of patients in the published reports in which these values were given.

values for parients in this series.

tMedian values for patients in published reports. 
TABLE III Monoclonal protein studies in primary amyloidosis with cholestatic jaundice

\begin{tabular}{lllll}
\hline & This series & Published reports & Total & $(\%)$ \\
\hline M component & $1(\mathrm{n}=2)$ & $7(\mathrm{n}=9)$ & 8 & $(66)$ \\
Immunoelectrophoresis: & $2(\mathrm{n}=2)$ & $4(\mathrm{n}=5)$ & 6 & $(85)$ \\
$\quad$ Kappa & 2 & 1 & 3 & $(50)$ \\
$\begin{array}{l}\text { Lambda } \\
\text { Bence-Jones proteinuria }\end{array}$ & $2(\mathrm{n}=2)$ & $2(\mathrm{n}=4)$ & - & $(68)$ \\
\hline
\end{tabular}

$\mathrm{n}=$ Number of patients in which these studies were carried out.

The diagnosis was established in 18 of the 25 patients before death but in only five $(20 \%)$ did the diagnosis antedate the first appearance of jaundice. In six of the patients the correct diagnosis was initially missed in spite of adequate histology. 269

Of the 25 patients, $16(65 \%)$ received no treatment. The others were treated with prednisolone alone; melphalan and prednisolone; cyclophosphamide and prednisolone; melphalan, prednisolone, and colchicine; and dimethyl-sulphoxide (DMSO), but in none was there any clear symptomatic or biochemical improvement with these regimens.

The platelet count was raised in two of the present cases $\left(558-602 \times 10^{9} / 1\right)$ but not in any other of the series. Albumin concentrations were low in 17 of the 23 patients $(74 \%)$ in whom there were recorded, in part related to the presence of a nephrotic syndrome. Hypogammaglobulinaemia was present in eight of 15 patients. One of our patients had a normal serum protein electrophoresis but immunofixation showed kappa Bence-Jones proteinuria (case 2).

Extrahepatic biliary obstruction was ruled out in all the patients by liver ultrasound, laparotomy, endoscopic retrograde cholangiography, or necropsy examination.

The salient histopathological abnormalities in the present cases were generalised, perisinusoidal deposition of amyloid, parallelled by advanced hepatocellular atrophy. Bile stasis was also seen in all the cases, albeit of variable degree. A slight predilection for amyloid deposition in the portal region was seen, in agreement with most previous reports. As in two exceptional cases, ${ }^{27}$ predominant centrilobular amyloid deposits were present in one of our patients (case 2). Vascular deposition was noted in all of the present cases but was reported in only eight of the 14 cases in the published reports that included detailed histological descriptions. Periductal amyloid was a feature in one case reported by Rubinow et al (case no 3).

The median time from the development of jaundice to death was 3 months (range

TABLE IV Histopathological features of liver biopsies in patients with primary amyloidosis and cholestatic jaundice

\begin{tabular}{lllll}
\hline & This series & Published reports & Total & $(\%)$ \\
\hline Atrophy & 5 & $16(n=16)$ & 21 & $(100)$ \\
Distribution: & 5 & $19(n=19)$ & 24 & $(100)$ \\
$\quad$ Diffuse & 5 & $1(n=10)$ & 2 & $(13)$ \\
Centrilobular & 1 & $9(n=10)$ & 13 & $(86)$ \\
Periportal & 4 & $1(n=19)$ & 1 & $(4)$ \\
Not specified & - & $8(n=14)$ & 13 & $(68)$ \\
Perivascular & 5 & $2(n=4)$ & 3 & $(33)$ \\
\hline
\end{tabular}

$\mathrm{n}=$ Denotes number of patients in which specific details were mentioned.

This series - the results were based on the five patients presented.
0.5-15). The most frequently recorded immediate cause of death was renal failure (14 patients), although most had a progressive deterioration in liver function before the final oliguria. Hepatorenal failure was reported in five patients, liver failure in one, and congestive cardiac failure in two. One patient died of spontaneous intrahepatic haemorrhage and in two the cause was not specified.

\section{Discussion}

The most common amyloid syndromes are the result of infiltration of the kidneys, heart, and peripheral nervous system. ${ }^{12}$ Amyloid deposition in the liver is also a frequent finding in patients with both $\mathrm{AL}$ and $\mathrm{AA}$ amyloidosis. Originally thought to be more frequent in secondary amyloidosis, ${ }^{13} 14$ a careful examination by Cohen and Skinner showed that hepatic amyloid deposition is a universal phenomenon, although the distribution and extent of deposition may vary. ${ }^{15}$ Although hepatic involvement can be massive, clinical manifestations including cholestasis as in the present cases are rare. In a series of 229 patients with primary amyloidosis, Kyle reported an incidence of hepatomegaly of 34\% with a modestly raised ALP activity in $16 \%$ of the patients. Hyperbilirubinaemia was present in only $4 \%$ of the cases. ${ }^{11}$ In 1988 Gertz et al presented a series of 80 patients with AL amyloidosis in which hepatic involvement was a dominant feature leading to the diagnosis. ${ }^{16}$ The median age of presentation was 59 years (range 37-80) with an approximately equal sex distribution (42 men, 38 women). Hepatomegaly was present in $83 \%$ of the patients but splenomegaly was relatively uncommon $(10 \%)$. Liver function test abnormalities were surprisingly mild or absent, the most conspicuous being a raised ALP or AST activities. Serum bilirubin concentrations were virtually always normal - only $8 \%$ had a value above $30 \mu \mathrm{mol} / \mathrm{l}$, and in only three patients did values exceed $100 \mu \mathrm{mol} / \mathrm{l}$. From what can be gathered from these and other large clinical series ${ }^{1}$ the overall prevalence of jaundice in $\mathrm{AL}$ amyloidosis is less than $5 \%$. Ascites is also relatively uncommon and mild $\left(10 \%-20 \%\right.$ of the patients). ${ }^{17} 18$ It is usually attributed to congestive heart failure or nephrotic syndrome and occasionally to portal hypertension which is extremely rare. Itescu in his review of the reports described nine such patients, ${ }^{19}$ and more recently there was a case report from Japan ${ }^{20}$ of a patient with $\mathrm{AL}$ amyloidosis, portal hypertension, and bleeding oesophageal varices in whom an intrahepatic arterio-portal shunt was found at angiography.

One feature of note is the occurrence of a low globulin level and the occasional finding of a high platelet count, both of which are unusual in chronic liver disease with splenomegaly. The hypogammaglobulinaemia probably signifies an increased urinary loss or suppression of normal immunoglobulin synthesis by an abnormal plasma cell clone, while the raised platelet count probably represents a degree of functional hypo- 
splenism. Of interest in the present patients, was the heterogeneity in the Congophilia and in the amount and intensity of the birefringent material present in the Congo red positive areas, particularly in the perisinusoidal deposits. Such a finding has been recently described $^{21}$ in a patient with light chain deposition disease (LCDD) and AL amyloidosis who presented with jaundice and hepatomegaly. This lack of tinctorial uniformity could be related to the codeposition of AL amyloid and non-amyloid light chains.

To explain the pathogenesis of severe cholestatic jaundice, a mechanical impedance to bile flow at the level of the bile canaliculi or further at the smaller ducts has been postulated. Confirmation of this hypothesis by electron microscopic examination was not found in the two cases actually studied. ${ }^{722}$ Moreover it does not explain why most patients with extensive amyloid liver deposits show no jaundice or raised alkaline phosphatase activities. It is interesting to note that functional derangement of renal tubular epithelium in patients with Bence-Jones proteinuria has been reported. ${ }^{23}$ In addition, inhibition of active transport sodiumpotassium ATPase by myeloma protein in rat renal cortical tubes has been shown in vitro. ${ }^{24}$ In a similar way, modified light chains might be able to induce functional alterations of the liver resulting in cholestasis or even jaundice.

Although a liver biopsy is said to carry an added risk in patients with amyloidosis, none of those who underwent the procedure suffered complications. In two of our patients (cases 3 and 5) a prolonged bleeding time precluded the procedure, and the diagnosis was not made until after death. Tissue other than liver might yield the diagnosis. Recently, subcutaneous fat aspiration was reported to be as sensitive as a rectal biopsy and even more than bone marrow for the detection of amyloid. ${ }^{26}$ The mean survival of patients with primary amyloidosis has been reported to be 12 months from the time of diagnosis ${ }^{11}$ and nine months for those with significant hepatic involvement. ${ }^{16}$ In 1986 Kyle et al established that the major risk factor affecting survival during the first year from diagnosis was the presence of congestive cardiac failure, followed by hepatomegaly, urinary light chains, and underlying myeloma. ${ }^{25}$ Inexplicably, the presence of a monoclonal protein seemed to have a protective effect on survival but only during the first year from diagnosis. Patients with congestive heart failure had a median survival of four months, which parallels the survival of those with cholestatic jaundice.

To date there is no specific treatment for AL amyloidosis, ${ }^{15}$ and all treatment modalities failed in this particular subgroup.

1 Levy M, Fryd C, Eliakim M. Intrahepatic obstructive jaundice due to amyloidosis of the liver. A case report and review of the literature. Gastroenterology 1971; 61 (2): 234-8.

2 Rubinow A, Koff R, Cohen A. Severe intrahepatic cholestasis in primary amyloidosis. A report of four cases and review of the literature. Am f Med 1978; 64: 937-46.

3 Melkebeke P, Vandepitte J, Hannon R, Fevery J. Huge hepatomegaly, jaundice and portal hypertension due to amyloidosis of the liver. Digestion 1980; 20: 351-7.

4 Rubio P, Farrell E, Lehane D. Primary liver amyloidosis producing obstructive jaundice. South Med $\mathcal{f} 1982 ; 72$ : 891-2.

5 Cox R. Amyloidosis of the liver causing jaundice. Postgrad Med f 1982; 58: 192-3.

6 Melato M, Manconi R, Magris D, Morassi P, Benussi DG, Tiribelli C. Different morphologic aspects and clinical features in massive hepatic amyloidosis. Digestion 1984; 29: $138-45$.

7 Finkelstein S, Fornasier V, Pruzanski W. Intrahepatic cholestasis with predominant pericentral deposition in systemic amyloidosis. Hum Pathol 1981; 12: 470-2.

8 Konikoff R, Mor C, Stern S, Shaklai M, Halevy J, Theodor E. Cholestasis and liver failure with lambda-AL amyloidosis. Gut 1987; 28: 903-6.

9 Hoffman N, Stein B, Davidan M, Rosenthal W. Hepatic amyloidosis presenting as severe intrahepatic cholestasis: A case report and review of the literature. $A m$ Gastroenterol 1988; 83 (7): 783-5.

10 Pepys MB. Amyloidosis: some recent developments. Quarterly fournal of Medicine April 1988 New series; 67: 283-98.

11 Kyle R, Griepp P. Amyloidosis (AL). Clinical and laboratory features in 229 cases. Mayo Clin Proc 1983; 58. tory fea $665-83$.

12 Griepp P. Amyloidosis (AL). An approach to early diagnosis. Arch Intern Med 1984; 144: 2145-6.

13 Bero GL. Amyloidosis: Its clinical and pathologic manifestations with a report of 12 cases. Ann Intern Med 1957; 46: 931-55

14 Briggs GW. Amyloidosis. Ann Intern Med 1957; 55 (6) 943-57.

15 Cohen A, Skinner M. Amyloidosis of the liver. In: Schiff L, Schiff ER, ed. Diseases of the liver. 5th Ed. Philadelphia: JB Lipincott, 1982: 1081-99.

16 Gertz M, Kyle R. Hepatic amyloidosis (primary [AL], immunoglobulin light chain): The natural history in 80 patients. Am 7 Med 1988; 85: 73-80.

17 Levy M, Pollack A, Lender $M$. The liver in amyloidosis. Digestion 1974; 10: 40-51.

18 Gregg J, Herskovic T, Bartholomew L. Ascites in systemic amyloidosis. Arch Intern Med 1965; 116: 605-10.

19 Itescu S. Hepatic amyloidosis. An unusual case of ascites and portal hypertension. Arch Intern Med 1984; 144 2257-9.

20 Aramaki $T$, Terade $H$, Okumura $H$, Tsutsui $H$, Fujita $S$, Tajiri $\mathrm{T}$, et al. Portal hypertension secondary to intrahepatic arterio-portal shunt in primary amyloidosis: a case report. Gastroenterol Ұpn 1989; 24 (4): 410-3.

21 Faa G, Van Eyken P, De Ros R, Fevery J, Van Damme B, De Groote J, Desmet VJ. Light chain deposition disease of the liver associated with AL type amyloidosis and severe the liver associated with Al type amylo

22 Mir-Madjlessi S, Farmer R, Hawk W. Cholestatic jaundice associated with primary amyloidosis. Cleve Clin $f \mathrm{Med}$ 1972; 39: 167-9.

23 Smithline N, Kassirer J, Cohen J. Light chain nephropathy. Renal tubular dysfunction associated with light chain proteinuria. N Eng f Med 1976; 294 (2): 71-4.

24 McGeoch D, Ledingham J, Falloner Smith J, Ross B. Inhibition of active transport sodium potassium ATPas by myeloma protein. Lancet 1978 ; ii: 17-8.

25 Kyle R, Griepp P, O’Fallon M. Primary systemic amyloidosis: Multivariate analysis for prognostic factors in 168 cases. Blood 1986; 68 (1): 220-4.

26 Gertz M, Ching Yang $\mathrm{Li}$, Tsuranobu S, Kyle R. Utility of subcutaneous fat aspiration for the diagnosis of systemic amyloidosis (Immunoglobulin light chain). Arch Intern Med 1988; 148: 929-33. 